\title{
REVIEW
}

\section{Lifestyle and dietary factors in the prevention of lethal prostate cancer}

\author{
Kathryn M Wilson ${ }^{1,3}$, Edward L Giovannucci ${ }^{1,2,3}$ and Lorelei A Mucci ${ }^{1,3}$ \\ The prevention of lethal prostate cancer is a critical public health challenge that would improve health and reduce suffering from this \\ disease. In this review, we discuss the evidence surrounding specific lifestyle and dietary factors in the prevention of lethal prostate \\ cancer. We present a summary of evidence for the following selected behavioral risk factors: obesity and weight change, physical \\ activity, smoking, antioxidant intake, vitamin D and calcium, and coffee intake.
}

Asian Journal of Andrology (2012) 14, 365-374; doi:10.1038/aja.2011.142; published online 16 April 2012

Keywords: epidemiology; diet; life style; obesity; physical activity; prevention; prostate cancer

\section{INTRODUCTION}

Prostate cancer is a major contributor to cancer incidence and mortality among men throughout the world, particularly in Westernized countries. ${ }^{1}$ Moreover, men with prostate cancer suffer significant impairments in quality of life, ${ }^{2}$ both from the disease itself and as a consequence of treatment. The disease is notable in its considerable biologic heterogeneity in metastatic potential over a man's lifetime. This heterogeneity is an important feature of the disease, and efforts to understand risk factors and predictors of more aggressive disease are central in prostate cancer research. The prevention of lethal prostate cancer represents an important public health challenge to reduce suffering from this disease. Moreover, the identification of lifestyle factors post-diagnosis that influence prostate cancer clinical course is appealing as a means of secondary prevention in combination with therapeutic intervention. In this paper, we present an overview of the evidence around selected exposures in the prevention of lethal prostate cancer. Given the diversity of potential factors, we have elected to focus on lifestyle and dietary factors, and not to discuss the evidence for pharmacologic agents. Moreover, we highlight compelling factors that may influence cancer-specific mortality after diagnosis. We present risk factors for lethal prostate cancer that have received the greatest scrutiny within epidemiological studies, as well as discuss novel hypotheses for which there is more limited evidence: obesity and weight change, physical activity, smoking, antioxidant intake, vitamin D and calcium, and coffee intake.

\section{GLOBAL BURDEN OF PROSTATE CANCER}

An overview of the descriptive epidemiology of cancer sets the framework for understanding the global burden of this disease and its impact from a public health perspective. Moreover, a comparison of the patterns of incidence and mortality across populations, as well as trends over time can provide clues about the role of lifestyle factors in prostate cancer etiology.

\section{Incidence}

Prostate cancer is the most commonly diagnosed cancer among men globally, with almost one million new cases each year. ${ }^{3}$ In the United States, 240890 men are expected to be diagnosed in 2011, and an American man's lifetime risk of prostate cancer is one in six. ${ }^{4}$

More than any other malignancy, the burden of prostate cancer shows remarkable worldwide variation (Figure 1), with a more than 60 -fold difference in age-adjusted incidence rates between population groups with the highest (African-American men in the United States) and the lowest (Japanese and Chinese men living in their native countries) incidence of prostate cancer. Part of the variation in incidence rates across populations can be explained by differences in screening practices, particularly screening with prostate-specific antigen (PSA), which often diagnoses a significant proportion of otherwise latent prostate cancer. However, geographic differences in prostate cancer incidence and mortality were apparent prior to the introduction of PSA screening starting in the early 1990s, highlighting a potential role of environmental and lifestyle factors in the etiology of this disease. Results from migrant studies lend additional support to role of lifestyle factors in prostate cancer incidence. Prostate cancer rates increase among men moving from low-risk to high-risk countries compared to those in their native countries. ${ }^{5,6}$ Prostate cancer mortality rates also increase, lending further support for non-hereditary causes beyond any artifactual rise due to screening and enhanced detection.

Incidence rates have increased substantially over time. In the United States and other Western countries, this is likely due in part to the adoption of PSA testing. However, incidence rates have also increased in Japan and some other Asian and Eastern European countries where PSA testing is not widely used, reflecting changes in other factors ${ }^{7}$ (Figure 1). PSA screening has also led to a shift in stage presentation, with concomitant increase in the ratio of localized to advanced disease cases and a decrease in the age at diagnosis. ${ }^{8}$ Screening has also led to

${ }^{1}$ Department of Epidemiology, Harvard School of Public Health, Boston, MA 02115, USA; ${ }^{2}$ Department of Nutrition, Harvard School of Public Health, Boston, MA 02115, USA and ${ }^{3}$ Channing Laboratory, Brigham and Women's Hospital, Harvard Medical School, Boston, MA 02115, USA Correspondence: Dr LA Mucci (Imucci@hsph.harvard.edu)

Received: 29 November 2011; Revised: 11 January 2012; Accepted: 20 January 2012; Published online: 16 April 2012 


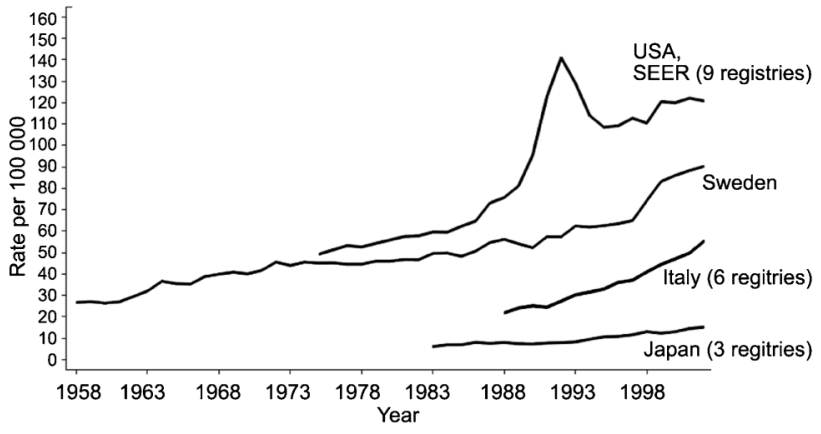

Figure 1 Trends in age-adjusted prostate cancer incidence rates over time in selected populations. Data from the International Agency for Research on Cancer, 2008.

the detection of a significant number of latent lesions that may never have come to light clinically nor harmed a man during his lifetime. ${ }^{9,10}$

The introduction of PSA screening has likely resulted in changes in the observed associations between specific dietary and lifestyle factors and prostate cancer risk over time. First, different factors may impact prostate cancer at various stages of progression, and therefore the associations may differ according to disease clinical characteristics, such as those defined by cancer stage or tumor grade. ${ }^{11}$ Indeed, it seems unlikely that the factors associated with development of indolent cancers would be similar to those associated with cancers demonstrating malignant potential. Since the majority of cancers diagnosed in the PSA era are well-differentiated tumors with low metastatic potential, it seems likely that associations observed in populations in mainly pre-PSA era populations would no longer be observed with respect to total prostate cancer risk.

\section{Mortality}

Based on 2008 data from the International Agency for Research on Cancer, an estimated 258000 men died of prostate cancer worldwide, ${ }^{3}$ with considerable variation in mortality rates among countries (Figure 2). Prostate cancer is the second most common cause of cancer death among men in the United States, with 33720 fatalities in $2011 .{ }^{4}$ During the past decade, prostate cancer mortality rates have shown declines in some countries, most notably in the United States (Figure 2). The reasons for this decline remain controversial, but may be attributable in part to earlier detection through PSA screening and subsequent earlier treatment. ${ }^{12}$



Figure 2 Trends in age-adjusted prostate cancer mortality rates over time in selected populations. Data from the International Agency for Research on Cancer, 2008
Notwithstanding the considerable mortality associated with this disease, most men die with and not from their cancer. Many prostate tumors remain indolent even in the absence of therapy. ${ }^{13,14}$ Indeed, cardiovascular disease and other chronic diseases are responsible for more than three-quarters of deaths among men diagnosed with localized prostate cancer.

In this paper, we define lethal prostate cancer as a cancer that forms overt metastases or leads to cancer-specific death. As not all studies have sufficient follow-up for cancer outcomes, we also present epidemiological studies that focus on surrogate endpoints such as biochemical recurrence, recognizing the potential limitations of this definition as an endpoint. The prevention of lethal prostate can come from two means. First, lifestyle or dietary factors at various points in a man's life may prevent the initiation of a tumor with a lethal potential from ever forming. This type of primary prevention is appealing as it eliminates the entire burden of the disease for men. Second, after a man is diagnosed with prostate cancer, lifestyle and dietary factors may influence a man's clinical course. Secondary prevention is attractive given that 4 million men are prostate cancer survivors living with a cancer diagnosis, of whom 2.4 million are in the United States. ${ }^{4}$

\section{ESTABLISHED RISK FACTORS FOR PROSTATE CANCER INCIDENCE}

Established risk factors for total prostate cancer risk are few and include: older age, race and family history. Moreover, there are a number of genetic risk loci that have been identified and confirmed in genome-wide association studies.

Older age is one of the strongest risk factors for prostate cancer. Prostate cancer rarely is diagnosed among men before the age of 40 years, and mortality is relatively rare before the age of 50 years. As with other epithelial cancers, incidence rates of prostate cancer increase exponentially from around the age of 55 years and onwards, a trend observed across multiple populations. Screening with PSA has led to a shift to an earlier average age of cancer diagnosis, with an estimated 10 year lead time.

Prostate cancer incidence and mortality rates differ by race/ethnicity. In the United States, incidence and mortality rates are the highest among African-American men. African-American men have mortality rates 2.4 times greater than those of Caucasian men. Both incidence and mortality rates are lower among Asian/Pacific-Islanders, Native Americans and Hispanic men than among non-Hispanic whites. ${ }^{4}$

Men with a family history of prostate cancer are at increased risk of prostate cancer diagnosis and mortality. Men whose father was diagnosed with prostate cancer have approximately twice the risk as men without a paternal family history. Having an affected brother increases the risk almost threefold. A family history in both the father and a brother increases risk of diagnosis almost ninefold. ${ }^{15}$ Family history is also associated with lethal prostate cancer. The risk of death from prostate cancer is approximately twofold higher for men with a father or a brother who died of prostate cancer, compared to men with prostate cancer who do not have a positive family history. ${ }^{16}$ However, the interpretation of self-reported family history of prostate cancer has become somewhat more difficult in the PSA era, because of the correlated exposure to PSA testing within families, and the increased use of PSA testing among men with a family history of prostate cancer. ${ }^{17}$

Data from twin studies suggest that the familial aggregation of prostate cancer incidence is in large part due to genetic factors. ${ }^{18}$ Indeed, prostate cancer is estimated to have one of the highest heritability, with more than $40 \%$ of prostate cancer variability attributed to 
genetic factors. During the last few years, genome-wide association studies have sought to identify common single-nucleotide polymorphisms (SNPs) associated with prostate cancer incidence. ${ }^{19}$ To date, 41 risk loci have been identified and confirmed across multiple studies, a number of loci greater than any other malignancy. It is estimated that these 41 loci explain about one-quarter of the variability if prostate cancer incidence that is attributed to genetic factors. It is noteworthy that the heritability of prostate cancer appears to be the results of small positive associations of low-penetrant genetic variants, rather than large associations with high-penetrance alleles.

The majority of the identified germline risk loci do not appear to be more strongly associated with lethal or nonlethal prostate cancer. ${ }^{20}$ However, family studies indicate a familial component of prostate cancer-specific survival. ${ }^{21}$ To date, only one genome-wide association study of lethal prostate cancer has been published. ${ }^{22}$ Although no SNPs reached genome-wide significance, three SNPs were associated with lethal prostate cancer at $10^{-5}$, and one of the three SNPs was subsequently validated in an independent cohort. One of the challenges in studying germline variants and prostate cancer survival is the identification of cohorts with sufficient numbers of cancer-specific events. Thus, additional collaborative research is needed to estimate the heritability of prostate cancer survival, as well as larger genomewide association studies of lethal disease.

\section{OVERVIEW OF RISK FACTORS FOR LETHAL PROSTATE CANCER}

Prostate cancer progression to lethal disease likely involves the activation of a number of different biological pathways. Risk factors for lethal prostate cancer and opportunities for prevention act through these pathways. In this paper, we focus on obesity and weight change, physical activity, smoking, antioxidants, vitamin D and calcium.

\section{Obesity}

Obesity is a major public health problem globally, with almost 1.5 billion adults estimated to be overweight or obese in $2008 .^{23}$ The increase in overweight and obesity in the United States in recent decades has been well documented. In the 2007-2008 National Health and Nutrition Examination Survey (NHANES), which measures height and weight on its participants, $34 \%$ of adults over the age of 20 years were obese defined as having a body mass index $(\mathrm{BMI}) \geqslant 30.0 \mathrm{~kg} \mathrm{~m}^{-2} .{ }^{24}$ In contrast, only $15 \%$ of adults were obese in the 1971-1980 NHANES I and II studies. The proportion of adults classified as overweight, with a BMI of $25.0-29.9 \mathrm{~kg} \mathrm{~m}^{-2}$, has been fairly constant over this time, at approximately one-third of the adult population. ${ }^{25}$

Obesity dysreglates multiple hormonal pathways and is associated with higher levels of insulin, lower levels of adiponectin, lower levels of testosterone and higher levels of inflammatory cytokines, all of which may be factors in prostate cancer progression. ${ }^{26-29}$ From a prevention perspective, it is notable that weight loss and physical activity are associated with positive changes in these biomarkers.

The relation between body size and incidence of prostate cancer is complex. ${ }^{11,26,30-33}$ However, obesity in adulthood has been associated with worse prostate cancer outcomes in most studies. Obese men are at higher risk of developing advanced stage prostate cancer and have higher rates of recurrence and cancer-specific mortality after diagnosis. A meta-analysis of six cohort studies of initially cancer-free men showed a significant $15 \%$ increase $(95 \%$ confidence interval (CI): 1.06-1.25) in the risk of fatal prostate cancer for each $5 \mathrm{~kg} \mathrm{~m}^{-2}$ increase in BMI. ${ }^{33}$ Similarly, among men with prostate cancer, a
$5 \mathrm{~kg} \mathrm{~m}^{-2}$ increase in BMI was associated with a 20\% (95\% CI: 0.99 1.46) increased risk of prostate cancer-specific mortality. ${ }^{33}$ There was some heterogeneity between studies included in this meta-analysis, which may be due to a large proportion of missing data on BMI in some study populations, and differences in follow-up time and the underlying prevalence of obesity between studies. Moreover, it is possible that some of the difference in study results is due to the effect of obesity on PSA levels; there is evidence that PSA concentrations are lower in obese men due to a larger blood volume, causing hemodilution of PSA levels. As a consequence, the sensitivity of PSA screening may be decreased among obese versus normal weight men. ${ }^{34,35}$

The poor prostate cancer outcomes associated with obesity do not appear to reflect solely differences in the efficacy of screening, as similar associations are seen between obesity and survival among men with disease, and adjusting for stage and grade at diagnosis. A study of 2546 men diagnosed with prostate cancer within the Physicians' Health Study found that prostate cancer-specific mortality was significantly associated with prediagnosis $\mathrm{BMI}^{26}$ (Figure 3 ). The relative risk of prostate cancer-specific mortality, adjusted for age at diagnosis and baseline smoking status was 1.5 (95\% CI: 1.2-1.9) for overweight men and 2.7 (95\% CI: 1.6-4.4) for obese men, compared to those with a healthy BMI. In this study, prediagnosis levels of C-peptide, a circulating marker of insulin secretion, were also associated with increased cancer-specific mortality, and men who were both overweight and who had high insulin levels were at particularly increased risk. It is possible that men who are obese and have higher C-peptide levels have a more metabolically active obesity than obese men with lower C-peptide measures, making the combined measure of BMI and C-peptide levels more predictive of prognosis.

Waist circumference (WC) and waist-to-hip ratio (WHR), measures of abdominal obesity, have been assessed in fewer studies than BMI. These measures of central obesity have generally not been associated with overall prostate cancer incidence. However, there is some evidence that abdominal obesity is associated with more advanced disease. In the European Prospective Investigation into Cancer and Nutrition (EPIC), a large cohort study of over 150000 men across Europe, WC and WHR were positively associated with diagnosis of more advanced prostate cancer (stage T3 or T4, or N1$\mathrm{N} 3$, or M1). ${ }^{36}$ A $5-\mathrm{cm}$ increase in waist circumference was associated with a 1.06 times greater risk of advanced prostate cancer $(95 \% \mathrm{CI}$ : 1.01-1.10), and a 0.1-unit greater waist to hip ratio was associated with a 1.21 times greater risk (95\% CI: 1.04-1.39). Waist circumference was significantly associated with more aggressive disease in the Melbourne Collaborative Cohort Study, ${ }^{37}$ but it was not associated with advanced stage or high-grade disease in the Health Professionals Follow-up

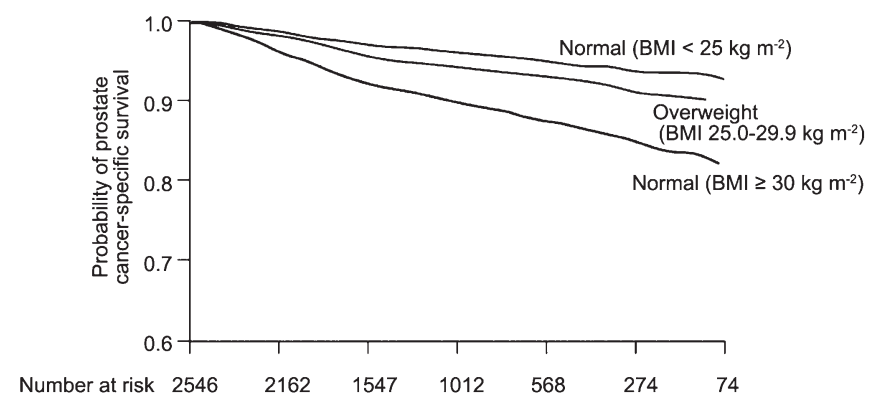

Figure 3 Prostate cancer-specific survival curves after diagnosis according to baseline BMI measured in 1982, controlling for age at diagnosis, smoking status, and time between BMI measurement and cancer diagnosis. From Ma et al. (2008). ${ }^{26}$ BMI, body mass index. 
Study. ${ }^{38}$ Because of the high correlation between BMI and measures of abdominal obesity, it is difficult to separate their effects. The EPIC study found that the waist circumference associations were stronger among men with lower BMI, suggesting a possible interaction between overall and abdominal obesity; however, the number of men in opposite extreme categories of BMI and waist was low.

The role of body size in childhood and early adulthood has also been studied. The Health Professionals Follow-up Study reported no overall association between childhood body size and prostate cancer risk, but a significantly lower risk of advanced and metastatic prostate cancer among men reporting larger body sizes at ages of 5, 10 and 20 years. ${ }^{38}$ A population-based case-control study in California found similar inverse associations with advanced prostate cancer for overweight and obesity at ages of 10 and 20 years. ${ }^{39}$ However, two other population-based case-control studies found no associations. ${ }^{40,41}$ It is possible that overweight and obesity in childhood and adolescence impact sex hormone levels during periods of growth and development important for later prostate cancer risk.

\section{Weight change}

The question of whether weight loss or weight gain in the time period just before and after prostate cancer diagnosis has been less studied than has body size. However, this is an important question, because if weight loss or weight gain has effects on prostate cancer survival, it would provide an important modifiable risk factor for men with prostate cancer. Several prospective cohort studies have examined adult weight change and the risk of prostate cancer. Overall, weight gain from early adulthood (age of 18 or 21 years) to mid-life was not associated with prostate cancer incidence in all $^{38,42-49}$ but one study. ${ }^{50}$ However, the AARP-NIH Diet and Health Study ${ }^{51}$ found that weight gain from the age of 18 year to the start of the study (at ages of 50-71 years) was significantly associated with an increased risk of prostate cancer mortality, although it was not associated with risk of total, localized, or extraprostatic disease, in line with other studies.

Only one study has examined weight change in the period shortly before and after prostate cancer diagnosis and the risk of recurrence, measured by a post-treatment PSA increase. ${ }^{52}$ This retrospective cohort study found that weight gain from 5 years before treatment by prostatectomy to 1 year after treatment was associated with a statistically significant increase in recurrence, while weight loss was nonstatistically significantly associated with a lower risk of recurrence (Figure 4). This study found no indication that physical activity modified the association between weight change and recurrence.

\section{Physical activity}

Physical activity has not been consistently associated with prostate cancer incidence. However, several studies have found that leisure time or recreational physical activity may reduce the risk of aggressive or advanced prostate cancer. The Health Professionals Follow-up Study (HPFS $)^{53}$ and the American Cancer Society Cancer Prevention Study II Nutrition Cohort (CPS II $)^{54}$ both reported lower risks of more advanced disease with increasing levels of recreational physical activity; these associations were independent of BMI. In the HPFS, men reporting 30 or more metabolic equivalent (Met)-hours per week of vigorous physical activity had a relative risk for fatal prostate cancer of 0.59 (95\% CI: $0.35-1.01$ ) compared to men reporting no recreational activity. In the CPS II study, men reporting greater than 35 Met-hours per week had a relative risk for aggressive cancer (high stage and/or grade) of 0.69 (95\% CI: 0.52-0.92). The EPIC

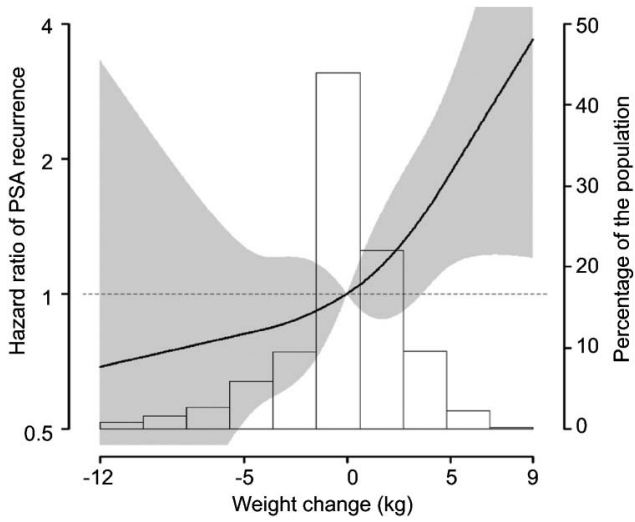

Figure 4 Hazard ratio of PSA recurrence by weight change from 5 years before to 1 year after prostatectomy (Joshu et al. ${ }^{52}$ ). PSA, prostate-specific antigen.

cohort found no association between recreational physical activity and advanced or high-stage disease; however, activity levels were substantially higher in this cohort, and the reference group included men with up to 25 Met-hours per week. In this cohort, the relative risk of advanced disease for the top versus lowest quartile of men $(>71$ Methours per week $v$ s. $\leqslant 25$ Met-hours per week) was 1.2 (95\% CI: 0.91.7), with a $P$ value for trend across quartiles of $0.16 .{ }^{55}$ On the other hand, the NIH-AARP Diet and Health Study found no association between vigorous exercise and risk of advanced or fatal prostate cancer. $^{56}$

The association between post-diagnosis physical activity and risk of prostate cancer mortality or recurrence among men with prostate cancer has been examined in only two studies. Among 2705 men with prostate cancer in the Health Professionals Follow-up Study, those who exercised vigorously for 3 or more hours per week had a $61 \%$ lower risk of prostate cancer-specific mortality than those with less than $1 \mathrm{~h}$ per week of vigorous activity (relative risk (RR): $0.4 ; 95 \%$ CI: $0.2-0.8){ }^{57}$ Both vigorous and non-vigorous activities were associated with a lower risk of all-cause mortality among these men with prostate cancer.

A study of prostate cancer progression, including a composite endpoint of biochemical recurrence, secondary treatments, bone metastasis, or cancer death, found that brisk walking was associated with a lower risk of recurrence (RR: 0.4; 95\% CI: 0.2-0.9) for brisk walking $\geqslant 3 \mathrm{~h}$ per week versus easy walking for $<3 \mathrm{~h}$ per week. There was a suggestion that vigorous physical activity was also associated with a lower risk of recurrence; however, few men in this study population engaged in vigorous physical activity. ${ }^{58}$

\section{Smoking}

Total prostate cancer incidence is not consistently associated with smoking. However, the latest review of evidence by the United States Surgeon General concluded that smoking is a 'probable' contributor to higher prostate cancer mortality rates. ${ }^{59}$ Studies of prostate cancer mortality have consistently found that smoking is associated with higher risk, with more recent smoking being more strongly associated. In the Health Professionals Follow-up Study, greater pack-years of smoking in the 10 years prior to prostate cancer diagnosis were associated with an increased risk of lethal disease, whereas smoking earlier than that and total lifetime smoking were not associated with risk. ${ }^{60}$ However, current smokers report less PSA testing than non-smokers, ${ }^{61}$ and the positive associations between smoking and prostate cancer mortality may be due in part to later diagnosis and treatment of these cancers among smokers. It is noteworthy that in the 
Health Professionals Follow-up Study, the association of prostate cancer with smoking was apparent even before PSA screening became available.

Smoking may also influence cancer-specific outcomes by influencing response to treatment. Studies in specific treatment populations have consistently reported worse outcomes for smokers than nonsmokers among prostate cancer patients treated with radiation, androgen deprivation therapy and radical prostatectomy. ${ }^{62-66}$ These studies were limited by low numbers of prostate cancer-specific deaths, and some relied on surrogate endpoints such as biochemical recurrence.

To date, only one large prospective study of smoking and cancerspecific mortality among men with prostate cancer has been published. ${ }^{67}$ Among 5366 men diagnosed with prostate cancer between 1986 and 2006 in the Health Professionals Follow-up Study, there were 524 prostate cancer deaths. The crude rate of prostate cancerspecific death was higher in current smokers than in never smokers (15.3 and 9.6 deaths per 1000 person-years, respectively). Adjusting for possible confounders, the relative risk of prostate cancer-specific mortality was 1.6 (95\% CI: 1.1-2.3) for current $v$ s. never smokers. The risk of cancer-specific death was still increased, but attenuated, when also adjusted for stage and grade that may indicate that part of the relationship between smoking and prostate cancer mortality is through its influence on these clinical parameters. Sensitivity analyses also found an increased risk of prostate cancer-specific mortality for current $v s$. never smokers when restricted to men diagnosed with nonmetastatic disease (stages T1-T3), and among men reporting a PSA test prior to diagnosis. Compared to current smokers, former smokers who quit 10 or more years before diagnosis and former smokers who had quit less than 10 years ago but smoked less than 20 pack-years overall had same risk as never smokers, again suggesting that more recent smoking behavior is the most relevant with respect to prostate cancer progression.

The possible biological basis for an association between smoking and risk of fatal prostate cancer or survival among men with prostate cancer is not clear, but several mechanisms have been proposed. ${ }^{67}$ Tumor promotion through carcinogens from tobacco smoke is a possibility, with several studies finding prostate cancer-specific mechanisms in animal and in vitro studies. In addition, nicotine may have epigenetic effects such as on gene methylation patterns, and effects on angiogenesis and tumor cell proliferation that contribute to initiation or progression of disease.

\section{Antioxidants}

Several dietary antioxidants, including selenium, vitamin E and lycopene/tomato sauce have been investigated with respect to prostate cancer incidence. Antioxidants are compounds that inhibit the oxidation of other species, thereby limiting the damaging effects of oxidation in animal tissues. Oxidative stress may damage molecules including proteins and DNA, and has been implicated in carcinogenesis.

Vitamin E and selenium. Vitamin E generally refers to a group of fatsoluble compounds that include tocopherols and tocotrienols. $\alpha$ tocopherol is the biologically most active form, and current dietary recommendations in the United States are based on $\alpha$-tocopherol alone. $\gamma$-tocopherol is the most common tocopherol in the United States diet. Possible anticarcinogenic actions of vitamin E include its ability to reduce DNA damage and inhibit malignant cellular transformation. ${ }^{68,69}$ In experimental models, derivatives of vitamin $\mathrm{E}$ inhibit growth induce apoptosis ${ }^{70}$ and enhance therapeutic effects in human prostate cancer cells. ${ }^{71}$
Secondary results of the Alpha-Tocopherol Beta-Carotene Cancer Prevention (ATBC) Study ${ }^{72}$ showed a $32 \%$ reduction in prostate cancer risk among men assigned to $\alpha$-tocopherol supplementation compared to placebo. ${ }^{73}$ Another large trial of a variety of nutrients found that vitamin $\mathrm{E}$ (in combination with selenium and $\beta$-carotene) reduced overall cancer mortality. ${ }^{74}$ These results, along with laboratory evidence and some epidemiologic support, motivated two trials of the effect of vitamin E supplementation on the risk of prostate cancer.

The Selenium and Vitamin E Cancer Prevention Trial (SELECT), planned for 7-12 years, was stopped early because of lack of efficacy for risk reduction. The initial report based on an average of 5.5 years of treatment, found a non-significant suggestion of increased prostate cancer risk among men receiving $400 \mathrm{IU}$ day $^{-1}$ of $\alpha$-tocopherol. ${ }^{75}$ With additional follow-up, the vitamin E group was found to have a significant increase in prostate cancer risk (RR: 1.17; 99\% CI: $1.004-$ 1.36; $P=0.008$, among 1149 cases).$^{76}$ Interestingly, there was not a statistically significant increased risk of prostate cancer in the vitamin E and selenium combination group (hazard ratio (HR): $1.05 ; P=0.46$ ), suggesting the two may interact. The Physicians Health Study II (PHS II) conducted contemporaneously with SELECT, found no effect on the incidence of prostate cancer (HR: $0.97 ; 95 \%$ CI: $0.85-1.09$; $P=0.58)$, with a dose of $400 \mathrm{IU}$ day $^{-1}$ for a median of 8 years of follow-up. $^{77}$

Of note, all men in the ATBC trial were smokers, and the prostate cancers were diagnosed outside the context of PSA screening, and thus, were generally aggressive. Interestingly, epidemiological studies of vitamin $\mathrm{E}$ and prostate cancer risk have had mixed results, generally pointing towards no overall association, but observed associations have generally been for advanced cancers and among smokers. In the VITamins And Lifestyle (VITAL) study, a cohort study specifically designed to examine supplement use and future cancer risk, a 10-year average intake of supplemental vitamin $\mathrm{E}$ was not associated with a reduced prostate cancer risk overall, but it was associated with a reduced risk for advanced prostate cancer (regionally invasive or distant metastatic, $n=123$ ) (HR: 0.43; 95\% CI: 0.19-1.0 for 10-year average intake $\geqslant 400$ IU day ${ }^{-1} v s$. non-use) ${ }^{78}$ In a prospective study of plasma vitamin $\mathrm{E}$ and prostate cancer mortality, there was a reduced risk associated with higher circulating levels limited to smokers, although the number of cases in the subgroup was small $(<30) .{ }^{79}$ Other epidemiological studies have similarly found a protective association limited to ever smokers, including prospective studies of dietary vitamin $\mathrm{E},{ }^{80}$ vitamin $\mathrm{E}$ through supplementation on lethal prostate cancer $^{81}$ and plasma $\alpha$-tocopherol levels and aggressive prostate cancer. ${ }^{82}$

The SELECT and PHS II trials were performed in the PSA screening era, and had small numbers of current smokers. Thus, neither trial could address the effect of $\alpha$-tocopherol specifically on advanced or fatal prostate cancers, or among current smokers.

The trace element selenium is not an anti-oxidant per se, but plays an important role as an essential element for the antioxidant enzyme glutathione peroxidase, ${ }^{83}$ as well as other selenoproteins involved in exerting antitumor effects, including apoptosis and inhibition of cellular proliferation. ${ }^{84,85}$ Dietary intake of selenium depends on the selenium content of soil in which foods are grown, which varies greatly by geographic area. Ecologic studies have suggested an inverse association between selenium soil content and prostate cancer incidence. ${ }^{86}$ Because selenium contents in specific foods vary as a function of the selenium content of the soil, epidemiological studies of selenium require biological sampling, primarily measuring levels in blood or toenails. Since the activity of some selenoenzymes plateau with a 
higher selenium level, ${ }^{87}$ the chemopreventive effect of selenium may be the greatest in populations with low selenium exposure. ${ }^{88}$

Like vitamin E, selenium was tested in the SELECT trial based on secondary results of other randomized trials. The Nutritional Prevention of Cancer Trial found a 63\% reduction in prostate cancer risk among men taking selenium supplements; ${ }^{89}$ with additional follow-up time, the protective effect was limited to those with low baseline levels of PSA or selenium. ${ }^{88}$ Another trial of selenium (with vitamin $\mathrm{E}$ and $\beta$-carotene) found a reduction in total cancer mortality in China. ${ }^{74}$ As discussed above, the SELECT trial was stopped early due to lack of efficacy of the supplements. With additional follow-up, there was still no association between selenium and prostate cancer risk. (RR: $1.09 ; 99 \%$ CI: 0.93-1.27; $P=0.18$ ).

Six prospective biomarker studies have reported significant associations between higher levels of selenium and reduced prostate cancer risk, ${ }^{90-95}$ particularly for advanced disease. ${ }^{90,91,94}$ Not all epidemiological studies have reported a protective association of selenium, however. ${ }^{96-98}$ Two recent randomized studies found no effect of selenium supplementation, alone or in combination, in reducing progression of high-grade prostatic intraepithelial neoplasia (PIN) to invasive cancer. ${ }^{99,100}$

Lycopene and tomato-based products. The relationship of tomatoes in prostate cancer prevention has been studied extensively in the epidemiological literature, with evidence suggesting a significant benefit associated with higher intake of tomatoes, particularly cooked tomatoes, or lycopene, a carotenoid with strong anti-oxidant effects. However, not all studies are supportive, and the association remains controversial.

A meta-analysis of studies on tomatoes and prostate cancer risk included results from 11 case-control and 10 prospective cohort or nested case-control studies that presented data on the intake of tomatoes, tomato products, or dietary lycopene. ${ }^{101}$ Compared with men with low intake of tomato products (the first quantile of intake), the relative (RR) of prostate cancer among consumers of higher amounts of raw tomato (the fifth quantile of intake) was 0.89 (95\% CI: 0.80$1.00)$. For cooked tomato products, which are more bioavailable sources of lycopene than fresh tomatoes, ${ }^{102}$ the summary RR was 0.81 (95\% CI: 0.71-0.92) comparing extreme categories of intake.

The results from cohort studies generally indicate a $25 \%-30 \%$ reduction in risk of prostate cancer, whereas dietary-based case-control studies are not supportive of an association. For example, the summary RR of prostate cancer from the meta-analysis related to an intake of one serving/day of raw tomato $(200 \mathrm{~g})$ was 0.97 (95\% CI: 0.85-1.10) for the case-control studies and 0.78 (95\% CI: 0.66-0.92) for cohort studies. ${ }^{101}$

The 2004 meta-analysis found an inverse association in studies of plasma lycopene and prostate cancer risk, with corresponding summary relative risks of 0.55 (95\% CI: $0.32-0.94)$ for case-control studies and 0.78 (95\% CI: $0.61-1.00)$ for cohort studies. ${ }^{101}$ An additional nested case-control study not included in the meta-analysis found a modest, not statistically significant, inverse association overall, and a significantly reduced risk with higher levels of plasma lycopene among men over 65 years old and among those without a family history of prostate cancer. ${ }^{103}$ However, several more recent studies have found no associations for serum lycopene. ${ }^{104-108}$ It is possible that these conflicting results are due, in part, to the changing mix of prostate cancer cases diagnosed in the United States with the advent of PSA screening. ${ }^{109}$ As a result of PSA screening, many more prostate cancers are being diagnosed, including a pool of biologically indolent cancers which would have gone undiagnosed in previous decades and in older studies.

Indeed, epidemiological studies generally point to a stronger reduction in risk of advanced stage or lethal prostate cancer, suggesting that tomato products and lycopene may play a role in prostate cancer progression. For example, in the Health Professionals Follow-up Study, the associations comparing high and low consumption of tomato sauce were $0.75(0.61-0.92)$ for total prostate cancer and $0.66(0.44-1.00)$ for advanced stage disease. ${ }^{110}$ In the EPIC study based on 966 total cases and 205 advanced stage cases of prostate cancer, there was no association between plasma lycopene and overall risk, but men in the top quintile of plasma lycopene had a significantly reduced risk of advanced stage prostate cancer (RR: 0.40 ; 95\% CI: 0.19 0.88)..$^{108}$

Although not definitive, the available data suggest that increased consumption of tomato and tomato-based products is associated with lower prostate cancer risk and progression. Whether the effect is driven through lycopene or other aspects of tomatoes remains undetermined. The relationship appears to be stronger for advanced prostate cancer than indolent disease.

\section{Calcium, dairy products and vitamin $\mathrm{D}$}

Calcium intake has been associated with an increased risk of prostate cancer in many but not all epidemiological studies. A meta-analysis of studies in 2005 found an increased risk of 1.39 (95\% CI: 1.09-1.77), for extreme categories of intake. ${ }^{111}$ Several studies have reported stronger associations between high intake of calcium and risks of aggressive forms of prostate cancer, defined by high grade, or advanced or lethal prostate cancer. ${ }^{11,112,113}$ The role of calcium is further supported by a recent study among African-American men in California, which included information on both calcium intake and vitamin $\mathrm{D}$ receptor calcium absorption genotype. ${ }^{114}$ Men with the vitamin D receptor Cdx2 GG genotype, poorer absorbers of dietary calcium, had a significantly lower risk of advanced prostate cancer (odds ratio (OR): 0.41; 95\% CI: 0.19-0.90) than those with the AA genotype. Men with higher intakes of dietary calcium were at increased risk of advanced disease in this study, and there was a significant gene-diet interaction, with a lower risk of advanced cancer among men with the GG genotype and lower dietary intakes.

The association between serum calcium and risk of prostate cancer has been studied in three prospective studies. Serum levels of calcium were associated with an increased risk of fatal disease in NHANES I and NHANES III. ${ }^{115,116}$ The adjusted relative risk of fatal prostate cancer was 2.68 (95\% CI: 1.02-6.99; $P=0.04$ ) for the top versus bottom tertile of total serum calcium in NHANES. In NHANES III, similar increases in risk were seen for both total serum calcium and ionized serum calcium, the biologically active component. A study in a large cohort of Swedish men found no association between serum calcium and overall risk of prostate cancer. Unfortunately, advanced and/or fatal prostate cancer were not able to be studied separately in this cohort. ${ }^{117}$ Circulating calcium levels are tightly regulated and are related to diet only at very high levels of intake, so it is unclear how this finding related to dietary calcium intake, if at all. However, it suggests a role for calcium, vitamin $\mathrm{D}$, and perhaps related factors, such as parathyroid hormone, in the etiology of lethal prostate cancer.

Dairy foods, a major dietary source of calcium, have also been associated with risk, with the 2005 meta-analysis reporting a summary relative risk of 1.11 (95\% CI: 1.03-1.19) for total dairy, 1.06 (95\% CI: 0.91-1.23) for milk and 1.11 (95\% CI: 0.99-1.25) per serving for cheese. ${ }^{111}$ Most, ${ }^{118,119}$ but not all ${ }^{120,121}$ studies published since this 
meta-analysis have tended to support an association between higher milk or dairy consumption and prostate cancer risk. The correlation between dairy foods and calcium and other nutrients creates challenges in trying to disentangle the independent effects of these compounds; however, cohort studies that have tried to separate effects generally suggest calcium may be the predominant player in explaining positive associations with prostate cancer. This is supported by a recent study of calcium intake among Singapore Chinese, a population in which dairy contributes little to total calcium intake. Even in this population, with comparatively low calcium intakes and in which vegetables were the main source of calcium, there was a suggestion of increased risk with higher calcium intakes. ${ }^{122}$

One proposed mechanism of calcium and prostate cancer is by suppressing circulating levels of dihydroxyvitamin $\mathrm{D}\left(1,25(\mathrm{OH})_{2} \mathrm{D}\right)$, the bioactive metabolite of vitamin D. It is involved in regulating cellular differentiation and proliferation of many cell types, including prostate epithelia. The main source of vitamin $\mathrm{D}$ is endogenous production in the skin resulting from sun exposure, and diet is a secondary source. $1,25(\mathrm{OH})_{2} \mathrm{D}$ is the most biologically active form, whereas $25(\mathrm{OH}) \mathrm{D}$ is found in much higher concentrations and better reflects sun and dietary exposure. ${ }^{123}$ An alternate hypothesis is that dairy protein increases levels of Insulin-like Growth Factor, ${ }^{124}$ which may thus influence risk of advanced or lethal prostate cancer. ${ }^{125}$

None of the studies of dietary or supplemental vitamin D have reported protective effects for prostate cancer incidence, ${ }^{126-129}$ and most of prediagnostic vitamin D metabolites have also reported null results. ${ }^{130-137}$ One recent nested case-control study of 1000 prostate cancer cases and 1000 controls within the ATBC study found an increased risk in the highest versus lowest serum levels of $25(\mathrm{OH}) \mathrm{D}$, with a relative risk of 1.56 (95\% CI: 1.15-2.12). ${ }^{138}$

There is some evidence that vitamin D plays a role in prostate cancer progression. Genetic variants in the vitamin D receptor are associated with Gleason score ${ }^{139}$ and genetic variants in the vitamin D pathway are associated with risk of recurrence or progression and prostate cancer-specific mortality. ${ }^{140}$ In addition, high expression of the vitamin D receptor protein in prostate cancer tissue has been associated with lower risk of lethal cancer among men with prostate cancer in the Health Professionals Follow-up Study and Physicians' Health Study. Men in the highest $v s$. lowest quartile of vitamin D receptor expression had a relative risk of 0.37 (95\% CI: 0.14-0.94), with adjustment for PSA at diagnosis, Gleason grade and stage. ${ }^{141}$ Another recent study of prostate cancer mortality nested in the HPFS and PHS found that prostate cancer patients with the lowest levels of prediagnostic $25(\mathrm{OH}) \mathrm{D}$ had a significantly greater risk of prostate cancer-specific mortality, with an RR of 1.59 (95\% CI: 1.06-2.39) for the highest vs. lowest quartiles. ${ }^{142}$ Prediagnostic vitamin D levels were significantly associated with both stage and grade in this study. Thus, while vitamin $\mathrm{D}$ exposure does not seem to be associated with lower risk of incident prostate cancer, several lines of evidence suggest that the vitamin D pathway may play a role in prostate cancer progression.

\section{Coffee}

There are several potential mechanisms by which coffee could be associated with a lower risk of lethal prostate cancer. Coffee is rich in several biologically active compounds including caffeine, minerals and phytochemicals. In observational and animal studies, long-term coffee drinking has been associated with improved glucose metabolism and insulin secretion in observational and animal studies. ${ }^{143}$ Moreover, coffee is a potent antioxidant ${ }^{144,145}$ and intake may be associated with levels of different sex steroid hormones. ${ }^{146,147}$
Most prior epidemiological studies of coffee and prostate cancer have focused on total incidence of disease. There have been to date three studies that have looked at lethal prostate cancer. Two studies ${ }^{148,149}$ reported no statistically significant associations of coffee consumption and prostate cancer mortality, although the studies were limited by a narrow range of coffee consumption, a small number of cancer-specific deaths, and inadequate adjustment for potential confounding by smoking and other factors. The Health Professionals Follow-up Study examined 47911 men who reported intake of regular and decaffeinated coffee in 1986 and every 4 years thereafter, and included 642 patients with lethal prostate cancer. ${ }^{150}$ After adjusting for potential confounding, men who consumed six or more cups of coffee per day had an $18 \%$ lower risk for prostate cancer overall (RR: 0.82; 95\% CI: $0.68-0.98)$ and a $60 \%$ lower risk of lethal prostate cancer (RR: 0.40; 95\% CI: 0.22-0.75) compared to nondrinkers. Intriguingly, the inverse association with lethal cancer was similar for men who drank either regular or decaffeinated coffee, suggesting that caffeine is not underlying the link. These intriguing data, while biologically plausible, need to be confirmed in additional study populations with large number of events and control for confounding.

\section{SUMMARY}

From a public health perspective, the prevention of lethal prostate is a paramount issue to improve the health of men in the United States and globally. Moreover, the identification of lifestyle factors after cancer diagnosis that could improve outcomes is appealing for the 4 million men currently living with a prostate cancer diagnosis. Research is in the early stages on both fronts, and research prerequisites include large, prospective cohort studies with long-term follow-up for cancer outcomes, detailed and updated questionnaire data, and consideration of the potential biases associated with epidemiological research. Still, there is now intriguing evidence that several behavioral risk factors may play a role in the prevention of lethal prostate cancer.

\section{COMPETING FINANCIAL INTERESTS}

None of the authors has any competing financial interests.

1 Ferlay J, Bray F, Pisani P, Parkin DM. GLOBOCAN 2002: Cancer Incidence, Mortality and Prevalence Worldwide. Lyon: IARC Press; 2004.

2 Steineck G, Helgesen F, Adolfsson J, Dickman PW, Johansson JE et al. Quality of life after radical prostatectomy or watchful waiting. N Engl J Med 2002; 347: 790-6.

3 Ferlay J, Shin HR, Bray F, Forman D, Mathers C, et al. GLOBOCAN 2008 v1.2, Cancer Incidence and Mortality Worldwide: IARC CancerBase No. 10 [Internet]. Lyon, France: International Agency for Research on Cancer; 2010. Available from: http:// globocan.iarc.fr, accessed on March 6, 2012

4 Howlader N, Noone A, Krapcho M, Neyman N, Aminou R et al. SEER Cancer Statistics Review 1975-2008, National Cancer Institute. Bethesda, MD, http://www.seer cancer.gov/csr/1975_2008/, based on November 2010 SEER data submission, posted to the SEER web site, 2011

5 Shimizu H, Ross RK, Bernstein L, Yatani R, Henderson BE et al. Cancers of the prostate and breast among Japanese and white immigrants in Los Angeles County. Br J Cancer 1991; 63: 963-6.

6 Yu H, Harris RE, Gao YT, Gao R, Wynder EL. Comparative epidemiology of cancers of the colon, rectum, prostate and breast in Shanghai, China versus the United States. Int J Epidemiol 1991; 20: 76-81.

7 Jemal A, Center MM, DeSantis C, Ward EM. Global patterns of cancer incidence and mortality rates and trends. Cancer Epidemiol Biomarkers Prev 2010; 19: 1893-907.

8 Etzioni R, Gulati R, Falcon S, Penson D. Impact of PSA screening on the incidence of advanced stage prostate cancer in the United States: a surveillance modeling approach. Med Decis Making 2008; 28: 323-31.

9 Ciatto S, Gervasi G, Bonardi R, Frullini P, Zendron P et al. Determining overdiagnosis by screening with DRE/TRUS or PSA (Florence pilot studies, 1991-1994). Eur J Cancer 2005; 41: 411-5.

10 Etzioni R, Penson DF, Legler JM, di Tommaso D, Boer R et al. Overdiagnosis due to prostate-specific antigen screening: lessons from U.S. prostate cancer incidence trends. J Natl Cancer Inst 2002; 94: 981-90. 
11 Giovannucci E, Liu Y, Platz EA, Stampfer MJ, Willett WC. Risk factors for prostate cancer incidence and progression in the health professionals follow-up study. Int $J$ Cancer 2007; 121: 1571-8.

12 Chu KC, Tarone RE, Freeman, HP. Trends in prostate cancer mortality among black men and white men in the United States. Cancer 2003; 97: 1507-16.

13 Albertsen PC, Hanley JA, Fine J. 20-year outcomes following conservative management of clinically localized prostate cancer. JAMA 2005; 293: 2095-101.

14 Johansson JE, Andren O, Andersson SO, Dickman PW, Holmberg L et al. Natural history of early, localized prostate cancer. JAMA 2004; 291: 2713-9.

15 Hemminki K, Czene K. Attributable risks of familial cancer from the Family-Cancer Database. Cancer Epidemiol Biomarkers Prev 2002; 11: 1638-44.

16 Brandt A, Sundquist J, Hemminki K. Risk for incident and fatal prostate cancer in men with a family history of any incident and fatal cancer. Ann Oncol 2012; 23: 251-6.

17 Ross LE, Berkowitz Z, Ekwueme DU. Use of the prostate-specific antigen test among U.S. men: findings from the 2005 National Health Interview Survey. Cancer Epidemiol Biomarkers Prev 2008; 17: 636-44.

18 Lichtenstein P, Holm NV, Verkasalo PK, Iliadou A, Kaprio J et al. Environmental and heritable factors in the causation of cancer-analyses of cohorts of twins from Sweden, Denmark, and Finland. N Engl J Med 2000; 343: 78-85.

19 Thomas G, Jacobs KB, Yeager M, Kraft P, Wacholder S et al. Multiple loci identified in a genome-wide association study of prostate cancer. Nat Genet 2008; 40: 310-5.

20 Pomerantz MM, Freedman ML. Genetics of prostate cancer risk. Mt Sinai J Med 2010; 77: 643-54.

21 Hemminki K. Familial risk and familial survival in prostate cancer. World J Urol 2011.

22 Penney KL, Pyne S, Schumacher FR, Sinnott JA, Mucci LA et al. Genome-wide association study of prostate cancer mortality. Cancer Epidemiol Biomarkers Prev 2010; 19: 2869-76.

23 Finucane MM, Stevens GA, Cowan MJ, Danaei G, Lin JK et al. National, regional, and global trends in body-mass index since 1980: systematic analysis of health examination surveys and epidemiological studies with 960 country-years and 9.1 million participants. Lancet 2011; 377: 557-67.

24 Flegal KM, Carroll MD, Ogden CL, Curtin LR et al. Prevalence and trends in obesity among US adults, 1999-2008. JAMA 2010; 303: 235-41.

25 Ogden CL, Carroll MD. CDC/NCHS Prevalence of Overweight, Obesity, and Extreme Obesity Among Adults: United States, Trends 1960-1962 Through 2007-2008, 2010.

26 Ma J, Li H, Giovannucci E, Mucci L, Qiu W et al. Prediagnostic body-mass index, plasma C-peptide concentration, and prostate cancer-specific mortality in men with prostate cancer: a long-term survival analysis. Lancet Oncol 2008; 9: 1039-47.

27 Li H, Stampfer MJ, Mucci L, Rifai N, Qiu W et al. A 25-year prospective study of plasma adiponectin and leptin concentrations and prostate cancer risk and survival. Clin Chem 2010; 56: 34-43.

28 Platz EA, Giovannucci E. The epidemiology of sex steroid hormones and their signaling and metabolic pathways in the etiology of prostate cancer. J Steroid Biochem Mol Biol 2004; 92: 237-.

29 de Marzo AM, Platz EA, Sutcliffe S, Xu J, Grönberg H et al. Inflammation in prostate carcinogenesis. Nat Rev Cancer 2007; 7: 256-69.

30 Discacciati A, Orsini N, Andersson SO, Andrén O, Johansson JE et al. Body mass index in early and middle-late adulthood and risk of localised, advanced and fatal prostate cancer: a population-based prospective study. Br J Cancer 2011; 105: 1061-8.

31 Maclnnis RJ, English DR. Body size and composition and prostate cancer risk: systematic review and meta-regression analysis. Cancer Causes Control 2006; 17: 989-1003.

32 Robinson WR, Poole C, Godley PA. Systematic review of prostate cancer's association with body size in childhood and young adulthood. Cancer Causes Control 2008; 19: 793-803.

33 Cao Y, Ma J. Body mass index, prostate cancer-specific mortality, and biochemical recurrence: a systematic review and meta-analysis. Cancer Prev Res (Phila) 2011; 4: 486-501.

34 Bañez LL, Hamilton RJ, Partin AW, Vollmer RT, Sun L et al. Obesity-related plasma hemodilution and PSA concentration among men with prostate cancer. JAMA 2007; 298: 2275-80.

35 Grubb RL 3rd, Black A, Izmirlian G, Hickey TP, Pinsky PF et al. Serum prostatespecific antigen hemodilution among obese men undergoing screening in the Prostate, Lung, Colorectal, and Ovarian Cancer Screening Trial. Cancer Epidemiol Biomarkers Prev 2009; 18: 748-51.

36 Pischon T, Boeing H, Weikert S, Allen N, Key T et al. Body size and risk of prostate cancer in the European prospective investigation into cancer and nutrition. Cancer Epidemiol Biomarkers Prev 2008; 17: 3252-61.

37 Maclnnis RJ, English DR, Gertig DM, Hopper JL, Giles GG. Body size and composition and prostate cancer risk. Cancer Epidemiol Biomarkers Prev 2003; 12: 1417-21.

38 Giovannucci E, Rimm EB, Stampfer MJ, Colditz GA, Willett WC. Height, body weight, and risk of prostate cancer. Cancer Epidemiol Biomarkers Prev 1997; 6: 557-63.

39 Robinson WR, Stevens J, Gammon MD, John EM. Obesity before age 30 years and risk of advanced prostate cancer. Am J Epidemiol 2005; 161: 1107-14.

40 Hsing AW, Deng J, Sesterhenn IA, Mostofi FK, Stanczyk FZ et al. Body size and prostate cancer: a population-based case-control study in China. Cancer Epidemio Biomarkers Prev 2000; 9: 1335-41.

41 Andersson SO, Baron J, Wolk A, Lindgren C, Bergström R et al. Early life risk factors for prostate cancer: a population-based case-control study in Sweden. Cancer Epidemiol Biomarkers Prev 1995; 4: 187-92.

42 Nomura A, Heilbrun LK, Stemmermann GN. Body mass index as a predictor of cancer in men. J Natl Cancer Inst 1985; 74: 319-23.
43 Cerhan JR, Torner JC, Lynch CF, Rubenstein LM, Lemke JH et al. Association of smoking, body mass, and physical activity with risk of prostate cancer in the lowa 65+ Rural Health Study (United States). Cancer Causes Control 1997; 8: 229-38.

44 Putnam SD, Cerhan JR, Parker AS, Bianchi GD, Wallace RB et al. Lifestyle and anthropometric risk factors for prostate cancer in a cohort of lowa men. Ann Epidemiol 2000; 10: 361-9.

45 Schuurman AG, Goldbohm RA, Dorant E, van den Brandt PA. Anthropometry in relation to prostate cancer risk in the Netherlands Cohort Study. Am J Epidemiol 2000; 151: 541-9.

46 Spitz MR, Strom SS, Yamamura Y, Troncoso P, Babaian RJ et al. Epidemiologic determinants of clinically relevant prostate cancer. Int J Cancer 2000; 89: 259-64.

47 onsson F, Wolk A, Pedersen NL, Lichtenstein P, Terry P et al. Obesity and hormonedependent tumors: cohort and co-twin control studies based on the Swedish Twin Registry. Int J Cancer 2003; 106: 594-9.

48 Friedenreich CM, McGregor SE, Courneya KS, Angyalfi SJ, Elliott FG. Case-control study of anthropometric measures and prostate cancer risk. Int J Cancer 2004; 110: 278-83.

49 Littman AJ, White E, Kristal AR. Anthropometrics and prostate cancer risk. Am J Epidemiol 2007; 165: 1271-9.

50 Hernandez BY, Park SY, Wilkens LR, Henderson BE, Kolonel LN. Relationship of body mass, height, and weight gain to prostate cancer risk in the multiethnic cohort. Cancer Epidemiol Biomarkers Prev 2009; 18: 2413-21.

51 Wright ME, Chang SC, Schatzkin A, Albanes D, Kipnis V et al. Prospective study of adiposity and weight change in relation to prostate cancer incidence and mortality. Cancer 2007; 109: 675-84

52 Joshu CE, Mondul AM, Menke A, Meinhold C, Han M et al. Weight gain is associated with an increased risk of prostate cancer recurrence after prostatectomy in the PSA era. Cancer Prev Res (Phila) 2011; 4: 544-51.

53 Giovannucci EL, Liu Y, Leitzmann MF, Stampfer MJ, Willett WC. A prospective study of physical activity and incident and fatal prostate cancer. Arch Intern Med 2005; 165: 1005-10.

54 Patel AV, Rodriguez C, Jacobs EJ, Solomon L, Thun MJ et al. Recreational physical activity and risk of prostate cancer in a large cohort of U.S. men. Cancer Epidemiol Biomarkers Prev 2005; 14: 275-9.

55 Johnsen NF, Tjønneland A, Thomsen BL, Christensen J, Loft S et al. Physical activity and risk of prostate cancer in the European Prospective Investigation into Cancer and Nutrition (EPIC) cohort. Int J Cancer 2009; 125: 902-8.

56 Moore SC, Peters TM, Ahn J, Park Y, Schatzkin A et al. Physical activity in relation to total, advanced, and fatal prostate cancer. Cancer Epidemiol Biomarkers Prev 2008; 17: 2458-66

57 Kenfield SA, Stampfer MJ, Giovannucci E, Chan JM. Physical activity and survival after prostate cancer diagnosis in the health professionals follow-up study. J Clin Oncol 2011; 29: 726-32.

58 Richman EL, Kenfield SA, Stampfer MJ, Paciorek A, Carroll PR et al. Physical activity after diagnosis and risk of prostate cancer progression: data from the cancer of the prostate strategic urologic research endeavor. Cancer Res 2011; 71: 3889-95.

59 US Department of Health and Human Services. The Health Consequences of Smoking. A Report of the Surgeon General. Washington, DC: US Dept of Health and Human Services; 2004.

60 Giovannucci E, Rimm EB, Ascherio A, Colditz GA, Spiegelman D et al. Smoking and risk of total and fatal prostate cancer in United States health professionals. Cancer Epidemiol Biomarkers Prev 1999; 8 (4 Pt 1): 277-82.

61 Byrne MM, Davila EP, Zhao W, Parker D, Hooper MW et al. Cancer screening behaviors among smokers and non-smokers. Cancer Epidemiol 2010; 34: 611-7.

62 Pickles T, Liu M, Berthelet E, Kim-Sing C, Kwan W et al. The effect of smoking on outcome following external radiation for localized prostate cancer. J Urol 2004; 171: 1543-6.

63 Moreira DM, Antonelli JA, Presti JC Jr, Aronson WJ, Terris MK et al. Association of cigarette smoking with interval to biochemical recurrence after radical prostatectomy: results from the SEARCH database. Urology 2010; 76: 1218-23.

64 Joshu CE, Mondul AM, Meinhold CL, Humphreys EB, Han M et al. Cigarette smoking and prostate cancer recurrence after prostatectomy. J Natl Cancer Inst 2011; 103: 835-8.

65 Pantarotto J, Malone S, Dahrouge S, Gallant V, Eapen L et al. Smoking is associated with worse outcomes in patients with prostate cancer treated by radical radiotherapy. BJU Int 2007; 99: 5649.

66 Oefelein MG, Resnick MI. Association of tobacco use with hormone refractory disease and survival of patients with prostate cancer. J Urol 2004; 171 (6 Pt 1): 2281-4.

67 Kenfield SA, Stampfer MJ, Chan JM, Giovannucci E. Smoking and prostate cancer survival and recurrence. JAMA 2011; 305: 2548-55.

68 Meydani M. Vitamin E. Lancet 1995; 345: 170-5.

69 Meydani SN, Hayek MG. Vitamin E and aging immune response. Clin Geriatr Med 1995; 11: 567-76

70 Gunawardena K, Murray DK, Meikle AW. Vitamin E and other antioxidants inhibit human prostate cancer cells through apoptosis. Prostate 2000; 44: 287-95.

71 Ripoll EA, Rama BN, Webber MM. Vitamin E enhances the chemotherapeutic effects of adriamycin on human prostatic carcinoma cells in vitro. J Urol 1986; 136: 529-31.

72 The effect of vitamin $E$ and beta carotene on the incidence of lung cancer and other cancers in male smokers. The Alpha-Tocopherol, Beta Carotene Cancer Prevention Study Group. N Engl J Med 1994; 330: 1029-35.

73 Heinonen OP, Albanes D, Virtamo J, Taylor PR, Huttunen JK et al. Prostate cancer and supplementation with alpha-tocopherol and beta-carotene: incidence and mortality in a controlled trial. J Natl Cancer Inst 1998; 90: 440-6. 
74 Blot WJ, Li JY, Taylor PR, Guo W, Dawsey S et al. Nutrition intervention trials in Linxian, China: supplementation with specific vitamin/mineral combinations, cancer incidence, and disease-specific mortality in the general population. J Nat Cancer Inst 1993; 85: 1483-92.

75 Lippman SM, Klein EA, Goodman PJ, Lucia MS, Thompson IM et al. Effect of selenium and vitamin $E$ on risk of prostate cancer and other cancers: the Selenium and Vitamin $E$ Cancer Prevention Trial (SELECT). JAMA 2009; 301: 39-51.

76 Klein EA, Thompson IM Jr, Tangen CM, Crowley JJ, Lucia MS et al. Vitamin E and the risk of prostate cancer: the Selenium and Vitamin E Cancer Prevention Trial (SELECT). JAMA 2011; 306: 1549-56.

77 Gaziano JM, Glynn RJ, Christen WG, Kurth T, Belanger C et al. Vitamins E and C in the prevention of prostate and total cancer in men: the Physicians' Health Study II randomized controlled trial. JAMA 2009; 301: 52-62.

78 Peters U, Littman AJ, Kristal AR, Patterson RE, Potter JD et al. Vitamin E and selenium supplementation and risk of prostate cancer in the Vitamins and lifestyle (VITAL) study cohort. Cancer Causes Control 2008; 19: 75-87.

79 Eichholzer M, Stähelin HB, Gey KF, Lüdin E, Bernasconi F. Prediction of male cancer mortality by plasma levels of interacting vitamins: 17-year follow-up of the prospective Basel study. Int J Cancer 1996; 66: 145-50.

80 Kirsh VA, Hayes RB, Mayne ST, Chatterjee N, Subar AF et al. Supplemental and dietary vitamin $\mathrm{E}$, beta-carotene, and vitamin $\mathrm{C}$ intakes and prostate cancer risk. J Nat/ Cancer Inst 2006; 98: 245-54.

81 Chan JM, Stampfer MJ, Ma J, Rimm EB, Willett WC et al. Supplemental vitamin E intake and prostate cancer risk in a large cohort of men in the United States. Cancer Epidemiol Biomarkers Prev 1999; 8: 893-9.

82 Gann PH, Ma J, Giovannucci E, Willett W, Sacks FM et al. Lower prostate cancer risk in men with elevated plasma lycopene levels: results of a prospective analysis. Cancer Res 1999; 59: 1225-30.

83 Combs GF Jr, Combs SB. The nutritional biochemistry of selenium. Annu Rev Nutr 1984; 4: 257-80.

84 Menter DG, Sabichi AL, Lippman SM. Selenium effects on prostate cell growth. Cancer Epidemiol Biomarkers Prev 2000; 9: 1171-82.

85 Redman C, Scott JA, Baines AT, Basye JL, Clark LC et al. Inhibitory effect of selenomethionine on the growth of three selected human tumor cell lines. Cancer Lett 1998; 125: 103-10.

86 Rayman MP. The importance of selenium to human health. Lancet 2000; 356: 233 41.

87 Neve J. Human selenium supplementation as assessed by changes in blood selenium concentration and glutathione peroxidase activity. J Trace Elem Med Biol 1995; 9 65-73.

88 Duffield-Lillico AJ, Dalkin BL, Reid ME, Turnbull BW, Slate E et al. Selenium supplementation, baseline plasma selenium status and incidence of prostate cancer: an analysis of the complete treatment period of the Nutritional Prevention of Cancer Trial. BJU Int 2003; 91: 608-12.

89 Clark LC, Combs GF Jr, Turnbull BW, Slate EH, Chalker DK et al. Effects of selenium supplementation for cancer prevention in patients with carcinoma of the skin. $A$ randomized controlled trial. Nutritional Prevention of Cancer Study Group. JAMA 1996; 276: 1957-63.

$90 \mathrm{Li} \mathrm{H}$, Stampfer MJ, Giovannucci EL, Morris JS, Willett WC, et al. A prospective study of plasma selenium levels and prostate cancer risk. J Natl Cancer Inst 2004; 96: 696-703.

91 Yoshizawa K, Willett WC, Morris SJ, Stampfer MJ, Spiegelman D et al. Study of prediagnostic selenium level in toenails and the risk of advanced prostate cancer. J Natl Cancer Inst 1998; 90: 1219-24.

92 Brooks JD, Metter EJ, Chan DW, Sokoll LJ, Landis P et al. Plasma selenium leve before diagnosis and the risk of prostate cancer development. J Urol 2001; 166 2034-8.

93 Helzlsouer KJ, Huang HY, Alberg AJ, Hoffman S, Burke A et al. Association between alpha-tocopherol, gamma-tocopherol, selenium, and subsequent prostate cancer. J Natl Cancer Inst 2000; 92: 2018-23.

94 Nomura AM, Lee J, Stemmermann GN, Combs GF Jr. Serum selenium and subsequent risk of prostate cancer. Cancer Epidemiol Biomarkers Prev 2000; 9: 883-7.

95 van den Brandt PA, Zeegers MP, Bode P, Goldbohm RA. Toenail selenium levels and the subsequent risk of prostate cancer: a prospective cohort study. Cancer Epidemiol Biomarkers Prev 2003; 12: 866-71.

96 Goodman GE, Schaffer S, Bankson DD, Hughes MP, Omenn GS et al. Predictors of serum selenium in cigarette smokers and the lack of association with lung and prostate cancer risk. Cancer Epidemiol Biomarkers Prev 2001; 10: 1069-76.

97 Hartman TJ, Albanes D, Pietinen P, Hartman AM, Rautalahti M et al. The association between baseline vitamin $\mathrm{E}$, selenium, and prostate cancer in the alpha-tocopherol, beta-carotene cancer prevention study. Cancer Epidemiol Biomarkers Prev 1998; 7 335-40.

98 Peters U, Takata Y. Selenium and the prevention of prostate and colorectal cancer. $\mathrm{Mo}$ Nutr Food Res 2008; 52: 1261-72.

99 Fleshner NE, Kapusta L, Donnelly B, Tanguay S, Chin J et al. Progression from highgrade prostatic intraepithelial neoplasia to cancer: a randomized trial of combination vitamin-E, soy, and selenium. J Clin Oncol 2011; 29: 2386-90.

100 Marshall JR, Tangen CM, Sakr WA, Wood DP Jr, Berry DL et al. Phase III Trial of Selenium to Prevent Prostate Cancer in Men with High-grade Prostatic Intraepithelial Neoplasia: SWOG S9917. Cancer Prev Res (Phila) 2011; 4: 1761-9.

101 Etminan M, Takkouche B, Caamano-Isorna F. The role of tomato products and lycopene in the prevention of prostate cancer: a meta-analysis of observational studies. Cancer Epidemiol Biomarkers Prev 2004; 13: 340-5.
102 Maiani G, Castón MJ, Catasta G, Toti E, Cambrodón IG et al. Carotenoids: actual knowledge on food sources, intakes, stability and bioavailability and their protective role in humans. Mol Nutr Food Res 2009; 53 Suppl 2: S194-218.

103 Wu K, Erdman JW Jr, Schwartz SJ, Platz EA, Leitzmann M et al. Plasma and dietary carotenoids, and the risk of prostate cancer: a nested case-control study. Cancer Epidemiol Biomarkers Prev 2004; 13: 260-9

104 Beilby J, Ambrosini GL, Rossi E, de Klerk NH, Musk AW. Serum levels of folate, lycopene, beta-carotene, retinol and vitamin $\mathrm{E}$ and prostate cancer risk. Eur J Clin Nutr 2010; 64: 1235-8.

105 Karppi J, Kurl S, Nurmi T, Rissanen TH, Pukkala E et al. Serum lycopene and the risk of cancer: the Kuopio Ischaemic Heart Disease Risk Factor (KIHD) study. Ann Epidemiol 2009; 19: 512-8.

106 Peters U, Leitzmann MF, Chatterjee N, Wang Y, Albanes et al. Serum lycopene, other carotenoids, and prostate cancer risk: a nested case-control study in the prostate, lung, colorectal, and ovarian cancer screening trial. Cancer Epidemiol Biomarkers Prev 2007; 16: 962-8.

107 Kristal AR, Till C, Platz EA, Song X, King IB et al. Serum lycopene concentration and prostate cancer risk: results from the Prostate Cancer Prevention Trial. Cancer Epidemiol Biomarkers Prev 2011; 20: 638-46

108 Key TJ, Appleby PN, Allen NE, Travis RC, Roddam AW et al. Plasma carotenoids, retinol, and tocopherols and the risk of prostate cancer in the European Prospective Investigation into Cancer and Nutrition study. Am J Clin Nutr 2007; 86: 672-81.

109 Giovannucci E. Commentary: serum lycopene and prostate cancer progression: a reconsideration of findings from the prostate cancer prevention trial. Cancer Causes Control 2011; 22: 1055-9.

110 Giovannucci E, Rimm EB, Liu Y, Stampfer MJ, Willett WC. A prospective study of tomato products, lycopene, and prostate cancer risk. J Natl Cancer Inst 2002; 94 391-8.

111 Gao X, LaValley MP, Tucker KL. Prospective studies of dairy product and calcium intakes and prostate cancer risk: a meta-analysis. J Natl Cancer Inst 2005; 97: 1768-77.

112 Giovannucci E, Liu Y, Stampfer MJ, Willett WC. A prospective study of calcium intake and incident and fatal prostate cancer. Cancer Epidemiol Biomarkers Prev2006; 15 203-10.

113 Tseng M, Breslow RA, Graubard BI, Ziegler RG. Dairy, calcium, and vitamin D intakes and prostate cancer risk in the National Health and Nutrition Examination Epidemiologic Follow-up Study cohort. Am J Clin Nutr 2005; 81: 1147-54.

114 Rowland GW, Schwartz GG, John EM, Ingles SA. Calcium intake and prostate cancer among African Americans: effect modification by vitamin $D$ receptor calcium absorption genotype. J Bone Miner Res; e-pub ahead of print 1 September 2011; doi: $10.1002 / \mathrm{jbmr} .505$.

115 Skinner HG, Schwartz GG. Serum calcium and incident and fatal prostate cancer in the National Health and Nutrition Examination Survey. Cancer Epidemiol Biomarkers Prev 2008; 17: 2302-5.

116 Skinner HG, Schwartz GG. A prospective study of total and ionized serum calcium and fatal prostate cancer. Cancer Epidemiol Biomarkers Prev 2009; 18: 575-8.

117 Halthur C, Johansson AL, Almquist M, Malm J, Grönberg H et al. Serum calcium and the risk of prostate cancer. Cancer Causes Control 2009; 20: 1205-14.

118 Allen NE, Key TJ, Appleby PN, Travis RC, Roddam AW et al. Animal foods, protein, calcium and prostate cancer risk: the European Prospective Investigation into Cancer and Nutrition. Br J Cancer 2008; 98: 1574-81.

119 Rohrmann S, Platz EA, Kavanaugh CJ, Thuita L, Hoffman SC et al. Meat and dairy consumption and subsequent risk of prostate cancer in a US cohort study. Cancer Causes Control 2007; 18: 41-50.

120 Park Y, Mitrou PN, Kipnis V, Hollenbeck A, Schatzkin A et al. Calcium, dairy foods, and risk of incident and fatal prostate cancer: the NIH-AARP Diet and Health Study. Am J Epidemiol 2007; 166: 1270-9.

121 Koh KA, Sesso HD, Paffenbarger RS Jr, Lee M. Dairy products, calcium and prostate cancer risk. Br J Cancer 2006; 95: 1582-5.

122 Butler LM, Wong AS, Koh WP, Wang R, Yuan JM et al. Calcium intake increases risk of prostate cancer among Singapore Chinese. Cancer Res 2010; 70: 4941-8.

123 Ali MM, Vaidya V. Vitamin D and cancer. J Cancer Res Ther 2007; 3: 225-30.

124 Giovannucci E, Pollak M, Liu Y, Platz EA, Majeed N et al. Nutritional predictors of insulin-like growth factor I and their relationships to cancer in men. Cancer Epidemiol Biomarkers Prev 2003; 12: 84-9.

125 Chan JM, Stampfer MJ, Ma J, Gann P, Gaziano JM et al. Insulin-like growth factor(IGF-I) and IGF binding protein-3 as predictors of advanced-stage prostate cancer. J Natl Cancer Inst 2002; 94: 1099-106.

126 Giovannucci E. Dietary influences of $1,25(\mathrm{OH}) 2$ vitamin $\mathrm{D}$ in relation to prostate cancer: a hypothesis. Cancer Causes Control 1998; 9: 567-82.

127 Chan JM, Giovannucci E, Andersson SO, Yuen J, Adami HO et al. Dairy products, calcium, phosphorous, vitamin D, and risk of prostate cancer (Sweden). Cancer Causes Control 1998; 9: 559-66.

128 Chan JM, Pietinen P, Virtanen M, Malila N, Tangrea J et al. Diet and prostate cance risk in a cohort of smokers, with a specific focus on calcium and phosphorus (Finland). Cancer Causes Control 2000; 11: 859-67.

129 Kristal AR, Cohen JH, Qu P, Stanford JL. Associations of energy, fat, calcium, and vitamin D with prostate cancer risk. Cancer Epidemiol Biomarkers Prev 2002; 11: 719-25.

130 Corder EH, Guess HA, Hulka BS, Friedman GD, Sadler M et al. Vitamin D and prostate cancer: a prediagnostic study with stored sera. Cancer Epidemiol Biomarkers Prev 1993; 2: 467-72.

131 Braun MM, Helzlsouer KJ, Hollis BW, Comstock GW. Prostate cancer and prediagnostic levels of serum vitamin D metabolites (Maryland, United States). Cancer Causes Control 1995; 6: 235-9. 
neg

Lifestyle, dietary factors in the prevention of lethal RCa

$\mathrm{KM}$ Wilson et al

374

132 Gen PH, Ma J, Hennekens CH, Hollis BW, Haddad JG et al. Circulating vitamin D metabolites in relation to subsequent development of prostate cancer. Cancer Epidemiol Biomarkers Prev 1996; 5: 121-6.

133 Nomura AM, Stemmermann GN, Lee J, Kolonel LN, Chen TC et al. Serum vitamin D metabolite levels and the subsequent development of prostate cancer (Hawaii, United States). Cancer Causes Control 1998; 9: 425-32.

134 Ahonen MH, Tenkanen L, Teppo L, Hakama M, Tuohimaa P. Prostate cancer risk and prediagnostic serum 25-hydroxyvitamin D levels (Finland). Cancer Causes Control 2000; 11: 847-52.

135 Tuohimaa P, Tenkanen L, Ahonen M, Lumme S, Jellum E et al. Both high and low levels of blood vitamin $D$ are associated with a higher prostate cancer risk: a longitudinal, nested case-control study in the Nordic countries. Int J Cancer 2004; 108: 104-8.

136 Platy EA, Leitzmann MF, Hollis BW, Willett WC, Giovannucci E. Plasma 1,25dihydroxy- and 25-hydroxyvitamin D and subsequent risk of prostate cancer. Cancer Causes Control 2004; 15: 255-65.

137 Jacobs ET, Giuliano AR, Martinez ME, Hollis BW, Reid ME et al. Plasma levels of 25hydroxyvitamin D, 1,25-dihydroxyvitamin $\mathrm{D}$ and the risk of prostate cancer. J Steroid Biochem Mol Biol 2004; 89-90: 533-7.

138 Albanes D, Mondul AM, Yuk K, Parisi D, Horst RL et al. Serum 25-hydroxy vitamin D and prostate cancer risk in a large nested case-control study. Cancer Epidemiol Biomarkers Prev 2011; 20: 1850-60.

139 Chen L, Davy Smith G, Evans DM, Cox A, Lawlor DA et al. Genetic variants in the vitamin $d$ receptor are associated with advanced prostate cancer at diagnosis: findings from the prostate testing for cancer and treatment study and a systematic review. Cancer Epidemiol Biomarkers Prev 2009; 18: 2874-81.

140 Holt SK, Kwon EM, Koopmeiners JS, Lin DW, Fens Z et al. Vitamin D pathway gene variants and prostate cancer prognosis. Prostate 2010; 70: 144860.
141 Hendrickson WK, Flavin R, Kasperzyk JL, Fiorentino M, Fang F et al. Vitamin D receptor protein expression in tumor tissue and prostate cancer progression. J Chin Oncol 2011; 29: 2378-85.

142 Fang F, Kasperzyk JL, Shui I, Hendrickson W, Hollis BW et al. Prediagnostic plasma vitamin $\mathrm{D}$ metabolites and mortality among patients with prostate cancer. PLOS ONE 2011; 6: e18625.

143 Tunnicliffe JM, Shearer J. Coffee, glucose homeostasis, and insulin resistance: physiological mechanisms and mediators. App Physio Nut Metal 2008; 33: 1290-300.

144 Silas A, Sakhi AK, Andersen LF, Silas T, Ström EC, et al. Intakes of antioxidants in coffee, wine, and vegetables are correlated with plasma carotenoids in humans. J Nut 2004; 134: 562-7.

145 Pulido R, Hernandez-Garcia M, Saura-Calixto F. Contribution of beverages to the intake of lipophilic and hydrophilic antioxidants in the Spanish diet. Eur J Chin Nut 2003; 57: 1275-82.

146 Svartberg J, Midtby M, Bona KH, Sundsfjord J, Joakimsen RM, et al. The associations of age, lifestyle factors and chronic disease with testosterone in men: the Proms $\varnothing$ study. Eur J Endocrinol 2003; 149: 145-52.

147 Hsieh CC, Signorello LB, Lipworth L, Lagiou P, Mantzoros CS, et al. Predictors of sex hormone levels among the elderly: a study in Greece. J Chin Epidemiol 1998;51:837-41.

148 Phillips RL, Snowdon DA. Association of meat and coffee use with cancers of the large bowel, breast, and prostate among Seventh-Day Adventists: preliminary results. Cancer Res 1983; 43 (5 suppl): 2403s-8s.

149 Using AW, McLaughlin JK, Schuman LM, Bjelke E, Gridley G, et al. Diet, tobacco use, and fatal prostate cancer: results from the Lutheran Brotherhood Cohort Study. Cancer Res 1990; 50: 6836-40.

150 Wilson KM, Kasperzyk JL, Rider JR, Kenfield S, van Dam RM, et al. Coffee consumption and prostate cancer risk and progression in the Health Professionals Follow-up Study. J Natl Cancer Inst. 2011; 103: 876-84.

Asian Journal of Andrology 